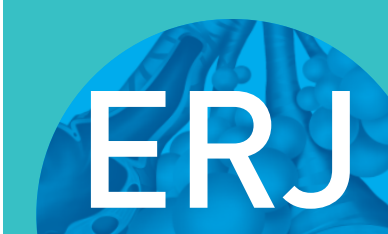

open research
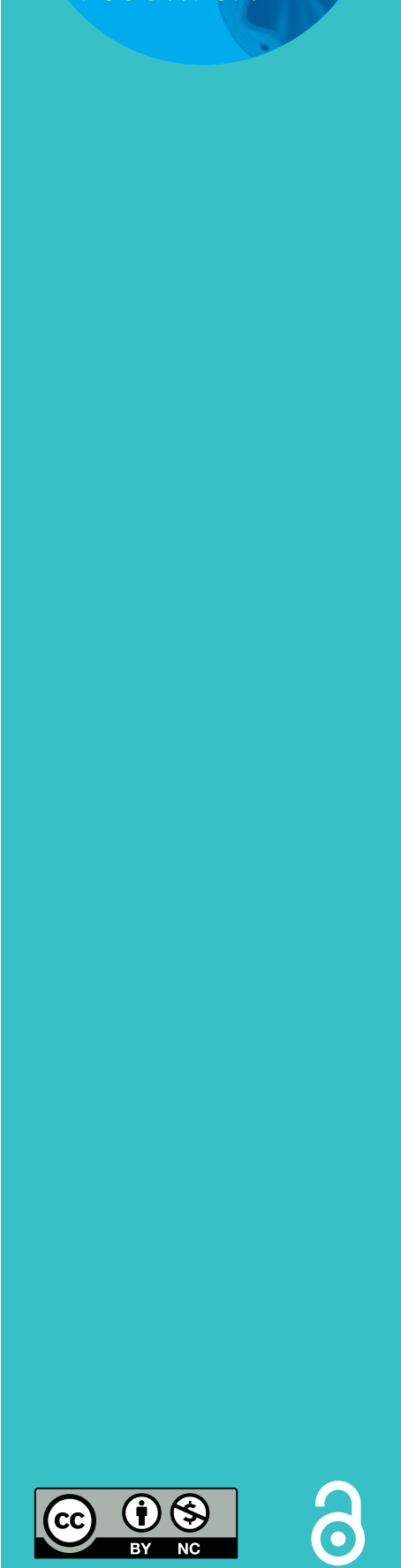

\section{Characterisation of pulmonary function trajectories: results from a Brazilian cohort}

\author{
Priscila Weber (1) 1 , Ana Maria Baptista Menezes ${ }^{1}$, Helen Gonçalves ${ }^{1}$, \\ Rogelio Perez-Padilla ${ }^{2}$, Deborah Jarvis ${ }^{3}$, Paula Duarte de Oliveira ${ }^{1}$ and \\ Fernando César Wehrmeister ${ }^{1}$
}

Affiliations: ${ }^{1}$ Postgraduate Program in Epidemiology, Federal University of Pelotas, Pelotas, Brazil. ${ }^{2}$ National Institute of Respiratory Diseases, Mexico City, Mexico. ${ }^{3}$ National Heart and Lung Institute, Imperial College, London, UK.

Correspondence: Priscila Weber, Postgraduate Program in Epidemiology, Marechal Deodoro St, $1169,3^{\circ}$ floor, Pelotas, Rio Grande do Sul, 96020-220, Brazil. E-mail: prifisio07dyahoo.com.br

\section{ABSTRACT}

Background: Pulmonary function (PF) trajectories are determined by different exposures throughout the life course. The aim of this study was to investigate characteristics related to PF trajectories from 15 to 22 years in a Brazilian cohort.

Methods: A birth cohort study (1993 Pelotas Birth Cohort) was conducted with spirometry at 15, 18 and 22 years. PF trajectories were built based on $\mathrm{z}$-score of forced expiratory volume in $1 \mathrm{~s}\left(\mathrm{FEV}_{1}\right)$, forced vital capacity (FVC) and their ratio using a group-based trajectory model. Associations with exposures reported from perinatal to 22 years were described.

Results: Three trajectories, low (LT), average (AT) and high (HT) were identified in 2917 individuals. Wealthiest individuals belonged to the HT of $\mathrm{FEV}_{1}(\mathrm{p}=0.023)$. Lower maternal pregestational body mass index (BMI) $(22.4 \pm 0.2 ; \mathrm{p}<0.001$ and $22.1 \pm 0.14 ; \mathrm{p}<0.001)$ and lower birth weight $(3164.8 \pm 25.4 ; \mathrm{p}=0.029$ and $3132.3 \pm 19.4 ; \mathrm{p}=0.005)$ were related to the $\mathrm{LT}$ of $\mathrm{FEV}_{1}$ and FVC. Mother's smoking exposure during pregnancy (37.7\%; $\mathrm{p}=0.002)$, active smoking at ages 18 and 22 years $(20.1 \%$ and $25.8 \% ; \mathrm{p}<0.001)$ and family history of asthma $(44.8 \%$; $<<0.001)$ were related to the LT of $\mathrm{FEV}_{1} / \mathrm{FVC}$. Wheezing, asthma and hospitalisations due to respiratory diseases in childhood were related to the LT of both $\mathrm{FEV}_{1}$ and $\mathrm{FEV}_{1} /$ FVC. Higher BMIs were related to the $\mathrm{HT}$ of $\mathrm{FEV}_{1}$ and $\mathrm{FVC}$ at all ages.

Conclusions: PF trajectories were mainly related to income, pregestational BMI, birth weight, hospitalisation due to respiratory diseases in childhood, participant's BMI, report of wheezing, medical diagnosis and family history of asthma, gestational exposure to tobacco and current smoking status in adolescence and young adult age.

@ERSpublications

In this study, three pulmonary function trajectories were observed from adolescence to early adulthood. The trajectories tracked over the years of follow-up and were characterised by several exposures from the gestational period until 22 years of age. https://bit.ly/2XMc4J4

Cite this article as: Weber $\mathrm{P}$, Menezes $\mathrm{AMB}$, Gonçalves $\mathrm{H}$, et al. Characterisation of pulmonary function trajectories: results from a Brazilian cohort. ERJ Open Res 2020; 6: 00065-2020 [https:// doi.org/10.1183/23120541.00065-2020].

This article has supplementary material available from openres.ersjournals.com

Received: 11 Feb 2020 | Accepted after revision: 26 May 2020

Copyright $\odot$ ERS 2020. This article is open access and distributed under the terms of the Creative Commons Attribution Non-Commercial Licence 4.0. 


\section{Introduction}

For many years, COPD was mainly explained by an accelerated loss of pulmonary function (PF) in adult smokers [1]. Recently, many studies have supported the existence of other PF trajectories patterns leading to several lung diseases in addition to COPD [2-4]. These trajectories are ones in which individuals experience a 'physiological' decline rate, having achieved only submaximal values of PF at the beginning of adulthood $[5,6]$.

Different PF trajectories are determined by different living conditions, shared habits and other exposures during the early-life PF developmental phase $[3,4,7,8]$. Considering the methodological challenges in evaluating repeated measures of PF, few longitudinal and population-based studies have investigated PF trajectories throughout the life course. Up to date, all published studies are based on populations living in high-income countries [3, 7-9].

Submaximal levels of forced expiratory volume in $1 \mathrm{~s}\left(\mathrm{FEV}_{1}\right)$ or forced vital capacity (FVC) at the beginning of adulthood are associated not only with respiratory diseases [3, 6-8] but also with premature death [10-13] and the occurrence of comorbidities, such as diabetes [6], cancer [11, 12] and cardiovascular diseases $[6,13]$. In this context, predicting the risky trajectories along with their associated determinants may inform measures to maximise the PF of adolescents and young adults and avoid future chronic diseases

The purpose of this study was to establish the PF growth trajectories from 15 to 22 years of age in the Pelotas 1993 Birth Cohort, Brazil, characterising them according to socioeconomic, gestational, perinatal, environmental, behavioural and health determinants during the life course.

\section{Methods}

We used data from the population-based Pelotas 1993 Birth Cohort, in Rio Grande do Sul state, Brazil. The cohort aimed to evaluate all live births between January 1 and December 31, 1993, whose mothers lived in the urban area of Pelotas municipality. Of the 5265 eligible pairs of mothers and children, 5249 individuals (99.7\%) were recruited at baseline. At 6 and 12 months and at 4 years of age, all newborns with low birth weight $(<2500 \mathrm{~g})$ and a random sample of $20 \%$ of the original cohort were included, $(\mathrm{n}=1460$ children). From 11 years onwards, all the original cohort members were evaluated. More cohort details can be found in a previous publication [14].

All the follow-up visits of the 1993 Pelotas Birth Cohort were approved by the Ethics and Research Committee of the Faculty of Medicine of the Federal University of Pelotas (UFPel), with the recent follow-up under the 1.250.366 protocol. Informed consent was obtained from all members of the cohort or their guardians when they were under-aged.

\section{Pulmonary function}

Spirometry was conducted at 15, 18 and 22 years of age using a portable spirometer (Easy-one, ndd Medical Technologies). A maximum of eight forced expiratory manoeuvres were performed, aiming for three acceptable manoeuvres with $<150 \mathrm{~mL}$ variation between the two highest measurements following the quality standards of the American Thoracic Society and the European Respiratory Society [15, 16]. We avoided spirometry in individuals with diagnosed cardiac alterations and those who reported thoracic, abdominal or ocular surgery, retinal displacement and hospitalisations due to cardiac problems in the last 3 months, pregnant women and individuals who were referred with active tuberculosis. Pre-bronchodilator values of $\mathrm{FEV}_{1}$ and FVC were expressed in $\mathrm{z}$-scores according to internal reference values generated from the standardised residuals of a linear regression with sex, skin colour and height as predictors.

\section{Characteristics of PF trajectory}

We used information on potential determinants of PF trajectory collected in either the perinatal period, at 6 and 12 months or 4,11,15, 18 and 22 years of age. All variables were collected through standardised measures and questionnaires.

From the perinatal follow-up interview, details on family income in minimum wages per month in Brazilian currency (a minimum wage equivalent to approximately US $\$ 84$ ), birth weight (g), prematurity (gestational age $<37$ weeks), pregestational body mass index (BMI), weight and height reported by mothers and calculated in $\mathrm{kg} \cdot \mathrm{m}^{-2}$, following the World Health Organisation (WHO) [17] standards, mother's and father's smoking and any maternal alcohol consumption during pregnancy were collected. Hospitalisations due to respiratory diseases (bronchitis, bronchiolitis, pneumonia and other respiratory diseases) from birth to 6 months and from 6 to 12 months were recorded. At 12 months, child's wheezing in the last 6 months and exposure to father's or mother's smoking after birth were also assessed and were all self-reported. 
At 4, 11, 15, 18 and 22 years of age, BMI was calculated in $\mathrm{kg} \cdot \mathrm{m}^{-2}$ and expressed as age-adjusted $\mathrm{z}$-scores, according to WHO guidelines [18]. Details about height and weight measurements are presented in the supplementary materials.

Self-reported physical activity from 11 to 22 years of age, was collected by a list of activities, and at age 18, using the International Physical Activity Questionnaire [19]. From these activities, frequency, duration and intensity were measured, generating a physical activity score in minutes per week according to WHO guidelines [20].

At 4, 11 and 15 years, wheezing in the last 12 months and diagnosis of asthma were collected. At the two older ages, allergy diagnosis was also reported. Family history of asthma was recorded at the 11-year follow-up. In the 4- and 11-year follow-ups, maternal and paternal smoking status were questioned. Hospitalisation cases due to respiratory diseases (asthma, wheezing and bronchitis) from 12 months to 4 years old were also assessed.

At 18 and 22 years old, we analysed smoking status, exposure to other resident's smoke at home, asthma and allergy diagnosis and wheezing reported in the last 12 months. Only at 18 years were the mother and father's smoking statuses recorded.

\section{Statistical analysis}

To assess selection bias, perinatal characteristics of cohort members included $(n=2917)$ and not included $(\mathrm{n}=2332)$ in the analysis were compared.

PF trajectories were identified by a group-based trajectory model approach [21]. The best model was chosen according to Bayesian and Akaike information criteria [22] but was also supported by other parameters [23]: 1) an average posterior probability; 2) the odds of correct classification; and 3) correspondence between estimated and assigned group probabilities (supplementary table S1). We compared the prevalence or characteristic means with each trajectory using the Chi-squared test and ANOVA. As participants with low birth weight were over-represented at 6 and 12 months and 4 years of age, when we included variables from these follow-ups, sample weights were applied to consider this oversampling. A significance level of $5 \%$ was considered as significant. All analyses were undertaken using Stata version 16 (StataCorp, College Station, TX, USA).

\section{Results}

The final sample consisted of 2917 individuals who had PF measurements in all follow-up visits. The study population differed from the nonrespondent's group in relation to income and maternal education (supplementary table S2). Those included were wealthier and were less likely to have mothers with a lower educational level.

For each PF parameter, three PF trajectories were identified (figure 1): low $(<-1 \mathrm{z}$-scores), average and high (>1 z-scores). Most individuals were classified in the AT of both $\mathrm{FEV}_{1,},(59.6 \%)$ and FVC (58.8\%) and in the HT of their ratio $(47.2 \%)$.

Gestational and perinatal characteristics and PF trajectories are shown in table 1. Income was higher in the HT $(4.66 \pm 0.22)$ and LT $(4.56 \pm 0.34)$ of $\mathrm{FEV}_{1}$ and lower in the AT $(4.04 \pm 0.12)(\mathrm{p}=0.023)$. No differences were observed for the other PF parameters. The proportion of men was lower in the AT of both FEV and $_{1}$ FVC $(45.6 \%$ and $45.9 \%$ respectively; $<<0.001)$ and in the HT of their ratio $(41.2 \%$; $<<0.001)$. Low maternal pregestational BMI $(22.4 \pm 0.2$ and $22.1 \pm 0.14)$ and lower birth weight $(3164.8 \pm 25.4$ and $3132.3 \pm 19.4)$ were associated with the $\mathrm{LT}_{\text {of }} \mathrm{FEV}_{1}$ and FVC, respectively. A higher proportion of mother's smoking exposure

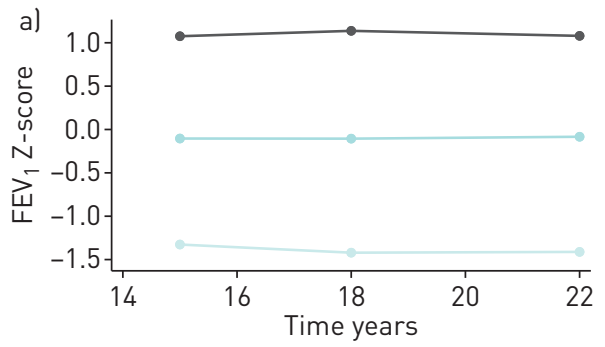

- Low $(15.5 \%)$ - Average (59.6\%) — High (24.9\%)

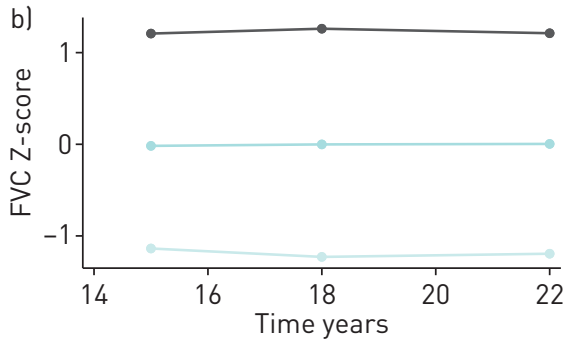

- Low $(22.4 \%)$ - Average $(58.8 \%)$ - High (21.9\%)

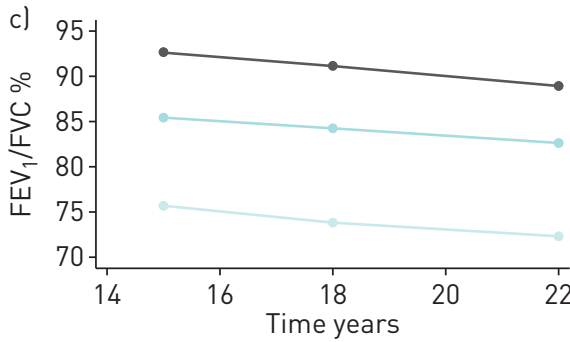

- Low $(8.5 \%)$ - Average $(44.3 \%)$ - High (47.2\%)

FIGURE 1 a) Pulmonary function (PF) trajectories based on forced expiratory volume in $1 \mathrm{~s}\left(\mathrm{FEV}_{1}\right)$ values expressed in z-scores; b) PF trajectories based on forced vital capacity (FVC) values expressed in Z-scores; C) PF trajectories based on FEV 1 / FVC ratio. 
TABLE 1 Description of the gestational and perinatal covariates for each group of pulmonary function trajectories: the 1993 Pelotas Birth Cohort, Brazil

\begin{tabular}{|c|c|c|c|c|c|c|c|c|c|c|c|c|}
\hline & \multicolumn{4}{|c|}{$\mathrm{FEV}_{1}$} & \multicolumn{4}{|c|}{ FVC } & \multicolumn{4}{|c|}{$\mathrm{FEV}_{1} / \mathrm{FVC}$} \\
\hline & $\begin{array}{l}\text { Low } \\
\mathrm{N}=\mathbf{4 3 5}\end{array}$ & $\begin{array}{l}\text { Average } \\
\mathrm{N}=1776\end{array}$ & $\begin{array}{l}\text { High } \\
\mathrm{N}=706\end{array}$ & p-value & $\begin{array}{l}\text { Low } \\
\mathrm{N}=635\end{array}$ & $\begin{array}{l}\text { Average } \\
\mathrm{N}=1657\end{array}$ & $\begin{array}{l}\text { High } \\
\mathrm{N}=625\end{array}$ & p-value & $\begin{array}{l}\text { Low } \\
\mathrm{N}=249\end{array}$ & $\begin{array}{l}\text { Average } \\
\mathrm{N}=1279\end{array}$ & $\begin{array}{c}\text { High } \\
\mathrm{N}=1389\end{array}$ & p-value \\
\hline $\begin{array}{l}\text { Income (minimum } \\
\text { wages) }{ }_{\uparrow \#}\end{array}$ & $4.56 \pm 0.34$ & $4.04 \pm 0.12$ & $4.66 \pm 0.22$ & 0.023 & $4.04 \pm 0.21$ & $4.27 \pm 0.13$ & $4.48 \pm 0.24$ & 0.381 & $4.54 \pm 0.42$ & $4.20 \pm 0.15$ & $4.27 \pm 0.15$ & 0.964 \\
\hline Male sex \% & $245(56.3)$ & $809(45.6)$ & $381(54.0)$ & $<0.001$ & 348 (54.8) & 760 (45.9) & 327 (52.3) & $<0.001$ & $153(61.4)$ & $710(55.5)$ & $572(41.2)$ & $<0.001$ \\
\hline Birth weight $g^{\text {I }}$ & $3164.8 \pm 25.4$ & $3175.8 \pm 12.4$ & $3232.0 \pm 19.8$ & 0.029 & $3132.3 \pm 19.4$ & $3195.1 \pm 13.0$ & $3224.8 \pm 21.6$ & 0.005 & $3240.1 \pm 37.3$ & $3204.3 \pm 14.7$ & $3163.3 \pm 13.7$ & 0.034 \\
\hline Prematurity $(\%)$ & $51(13.4)$ & $160(10.1)$ & 65 (10.2) & 0.151 & 71 (13.0) & 141 (9.5) & $64(11.2)$ & 0.072 & $30(13.1)$ & $106(9.3)$ & $140(11.4)$ & 0.144 \\
\hline $\begin{array}{l}\text { Pregestational BMI } \\
\mathrm{kg} \cdot \mathrm{m}^{-2} \uparrow\end{array}$ & $22.4 \pm 0.2$ & $22.8 \pm 0.1$ & $23.3 \pm 0.1$ & $<0.001$ & $22.1 \pm 0.14$ & $23.0 \pm 0.1$ & $23.3 \pm 0.15$ & $<0.001$ & $23.0 \pm 0.25$ & $23.1 \pm 0.10$ & $22.6 \pm 0.10$ & 0.006 \\
\hline \multicolumn{13}{|l|}{ Smoking in pregnancy \% } \\
\hline $1^{\circ}$ trimester & $133(30.6)$ & $499(28.1)$ & $220(31.0)$ & 0.252 & 177 (27.9) & $470(28.4)$ & 205 (32.8) & 0.081 & 94 (37.7) & $384(30.0)$ & 374 (26.9) & 0.002 \\
\hline $2^{\circ}$ trimester & $126(29.0)$ & $474(26.7)$ & $206(29.2)$ & 0.364 & $168(26.4)$ & $446(26.9)$ & $192(30.7)$ & 0.146 & 82 (32.9) & $360(28.1)$ & $364(26.2)$ & 0.079 \\
\hline $3^{\circ}$ trimester & $120(27.6)$ & $469(26.4)$ & $203(28.7)$ & 0.483 & $156(24.6)$ & $447(27.0)$ & $189(30.2)$ & 0.075 & 82 (32.9) & $353(27.6)$ & $357(25.7)$ & 0.055 \\
\hline Father's smoke \% & $182(41.8)$ & 815 (45.9) & 309 (43.9) & 0.259 & $283(44.5)$ & 750 (45.3) & $273(43.7)$ & 0.789 & 97 (38.9) & $568(44.4)$ & $641(46.1)$ & 0.103 \\
\hline Alcohol in pregnancy \% & $17(3.9)$ & $93(5.2)$ & $40(5.7)$ & 0.409 & $28(4.4)$ & $88(5.3)$ & $34(5.4)$ & 0.635 & $14(5.6)$ & $60(4.7)$ & $76(5.5)$ & 0.619 \\
\hline
\end{tabular}

Data are presented as mean \pm SD or $\mathrm{n}(\%)$, unless otherwise stated. $\mathrm{p}$-values were obtained by the Chi-squared test, unless otherwise stated. FEV ${ }_{1}$ : forced expiratory volume in $1 \mathrm{~s}$; FVC: forced vital capacity; BMI: body mass index. " : family income in minimum wages per month in Brazilian currency (a minimum wage equivalent to approximately US\$84). ": p-value obtained by ANOVA. N: absolute frequencies of individuals per pulmonary function (PF) trajectories based on the total sample (2197); $\mathrm{n}$ : absolute frequencies of the exposure covariables per PF trajectory. 
was observed in the $\mathrm{LT}$ of $\mathrm{FEV}_{1} / \mathrm{FVC}$ ratio during all gestational periods but was statistically significant only in the first trimester $(\mathrm{p}=0.002)$. No differences were found when father's smoke exposure was evaluated.

Table 2 describes the respiratory covariates, tobacco exposure after birth and physical activity and PF trajectories. The frequency of hospitalisations due to respiratory diseases was significantly higher in the LT of $\mathrm{FEV}_{1}$ at 6 months $(\mathrm{p}=0.027)$ and in the LT of $\mathrm{FEV}_{1} / \mathrm{FVC}$ ratio at 6 months $(\mathrm{p}=0.035)$ and 4 years of age $(p=0.001)$. At almost all evaluated ages, wheezing and asthma diagnoses were higher in the LT of both $\mathrm{FEV}_{1}$ and $\mathrm{FEV}_{1} / \mathrm{FVC}$ ratio. The latter was also related to a family history of asthma $(\mathrm{p}<0.001)$. Higher frequencies of allergy diagnosis were reported in the HT of $\mathrm{FEV}_{1}(\mathrm{p}=0.015)$ and $\mathrm{FVC}(\mathrm{p}=0.024)$ at ages 15 and 22 years, respectively and in the LT of their ratio at ages 11,18 and 22 years $(p<0.05)$. At 18 and 22 years, current smoking was strongly related to the $\mathrm{LT}$ of $\mathrm{FEV}_{1} / \mathrm{FVC}$ ratio $(\mathrm{p}<0.001)$. Despite not being statistically significant, the same can be applied to the HT of FVC at both ages. More active people were prevalent in the $\mathrm{LT}$ of $\mathrm{FEV}_{1} / \mathrm{FVC}$ ratio at $15(\mathrm{p}<0.001)$ and 18 years $(\mathrm{p}=0.021)$.

The relationship between BMI and PF trajectories are shown in figure 2. At all ages, higher BMI means were observed in the HT of $\mathrm{FEV}_{1}$ and FVC $(\mathrm{p}<0.001)$ and in the LT of their ratio $(\mathrm{p}<0.001)$. Figure 3 shows the individual obstruction status, represented by the $\mathrm{FEV}_{1} / \mathrm{FVC}$ ratio values for each $\mathrm{PF}$ trajectory. At all ages, lower percentage means of $\mathrm{FEV}_{1} / \mathrm{FVC}$ ratio were observed in the $\mathrm{LT}$ of $\mathrm{FEV}_{1}(\mathrm{p}<0.001)$ and in the HT of FVC $(\mathrm{p}<0.001)$.

\section{Discussion}

We observed three trajectories showing high, average and low patterns of PF. These trajectories were tracked over a 7-year period (figure 1). Following a lower trajectory from 15 to 22 years of age was associated with: lower income, mothers with lower pregestational BMI, lower birth weight, higher instances of hospitalisation due to respiratory diseases in childhood, lower BMI, more wheezing, medical diagnosis and family history of asthma, gestational exposure to tobacco and current smoking status. To the best of our knowledge, this is the first study to characterise PF trajectory groups in a birth cohort from a middle-income country.

The ability to detect PF trajectories in longitudinal data is dependent on the sample size and the number of measures on each individual [24]. In both the [7], Manchester Asthma Allergy Study Cohort (MASS) (1046 participants, PF measured at ages 5, 8, 11 and 16 years) and Avon Longitudinal Study of Parents and Children (ALSPAC) (1390 participants, PF measured at ages 8, 15 and 24 years), the authors observed four trajectories that were tracked over the observation period. Two of them presented persistently below average values until adulthood, and included more than half of the sample. The Tasmanian Longitudinal Health Study Cohort (TAHS) [3], described six PF trajectories (2438 participants, PF measured at 7, 13, $18,45,50$ and 53 years). Among these trajectories, around $42 \%$ of the sample presented PF trajectories always below the mean. Unlike our study, more than half of the sample presented average values of PF over time. The above-mentioned studies presented sample sizes similar to ours; however, they detected more trajectories and also a higher percentage of individuals with low PF due to a longer follow-up time that spanned childhood to the sixth decade of life [3] and into a slightly older age than our study [7]. The Tucson Children Respiratory Study (CRS) [8] (599 participants, PF measured from 11 to 32 years) and the Isle of Wight (IOW) cohort [9] (around 1000 participants, PF measured at 10, 18 and 26 years) only showed high and low PF trajectories, probably due to their small sample size.

A higher mean income was observed in individuals in the HT and LT of FEV (table 1). This result supports socioeconomic status as a determinant of $\mathrm{PF}$ as it can provide information regarding respiratory health inequalities [25]. However, as our results are not linear, further investigations could explore the role of socioeconomic status in lung function trajectories. A previous study in the same cohort showed that individuals in the lowest socioeconomic groups from birth to adolescence also had lower PF at age 15 years [26].

A lower maternal pregestational BMI was observed in the LT of FVC and $\mathrm{FEV}_{1}$ (table 1), and this can be explained by its association with birth weight. Maternal malnutrition may have a direct impact on birth weight as a result of nutrient-deficient transplacental transport [27]. In our cohort, lower maternal BMI was significantly associated with low birth weight (results not shown) which was also associated with the LT of both FVC and $\mathrm{FEV}_{1}$ in this study. Lower birth weight is a well-established risk factor for low PF in adulthood. A recent meta-analysis [28] showed a strong association of high birth weight and greater PF later in life. Similarly to our results, the IOW study [9] showed that low birth weight was strongly related to low trajectories of PF. Also, findings from the MASS and ALSPAC study [7], presented the same pattern, despite not being different statistically. 
TABLE 2 Description of the respiratory, smoke exposure and physical activity covariates collected after birth for each group of pulmonary function trajectories: the 1993 Pelotas Birth Cohort, Brazil

\begin{tabular}{|c|c|c|c|c|c|c|c|c|c|c|c|c|}
\hline & \multicolumn{4}{|c|}{ FEV $_{1}$} & \multicolumn{4}{|c|}{ FVC } & \multicolumn{4}{|c|}{$\mathrm{FEV}_{1} / \mathrm{FVC}$} \\
\hline & $\begin{array}{c}\text { Low } \\
\mathrm{N}=435\end{array}$ & $\begin{array}{l}\text { Average } \\
\mathrm{N}=1776\end{array}$ & $\begin{array}{c}\text { High } \\
\mathrm{N}=706\end{array}$ & p-value & $\begin{array}{c}\text { Low } \\
\mathrm{N}=635\end{array}$ & $\begin{array}{l}\text { Average } \\
\mathrm{N}=1657\end{array}$ & $\begin{array}{c}\text { High } \\
\mathrm{N}=625\end{array}$ & p-value & $\begin{array}{l}\text { Low } \\
\mathrm{N}=249\end{array}$ & $\begin{array}{l}\text { Average } \\
\mathrm{N}=1279\end{array}$ & $\begin{array}{c}\text { High } \\
\mathrm{N}=1389\end{array}$ & p-value \\
\hline \multicolumn{13}{|c|}{ Hospitalisation due to respiratory diseases } \\
\hline 6 months & $17(12.2)$ & 33 (6.3) & $9(4.0)$ & 0.027 & $18(8.3)$ & $35(7.1)$ & 6 (3.7) & 0.275 & $8(13.7)$ & $28(7.7)$ & $23(4.8)$ & 0.035 \\
\hline 12 months & $7(3.4)$ & $18(2.9)$ & $7(3.8)$ & 0.850 & $9(2.2)$ & 18 (3.5) & $5(3.6)$ & 0.661 & $2(3.8)$ & $14(3.4)$ & $16(2.9)$ & 0.914 \\
\hline 4 year & $22(14.9)$ & $64(11.0)$ & $13(6.1)$ & 0.073 & $22(7.2)$ & 62 (12.2) & $15(8.7)$ & 0.139 & 16 (22.8) & 44 (11.7) & $39(7.4)$ & 0.001 \\
\hline \multicolumn{13}{|c|}{ Wheezing (last 12 months) } \\
\hline 12 months & $68(54.1)$ & $228(46.6)$ & $80(43.1)$ & 0.134 & $85(48.1)$ & $223(47.7)$ & $68(43.1)$ & 0.605 & $38(58.6)$ & $159(48.9)$ & 179 (43.5) & 0.053 \\
\hline 4 years & $29(22.5)$ & $98(20.0)$ & $27(15.7)$ & 0.169 & $31(17.0)$ & 99 (21.5) & 24 (15.3) & 0.315 & $18(26.7)$ & 78 (23.9) & 58 (14.4) & 0.005 \\
\hline 11 years & $87(20.4)$ & $234(13.4)$ & $76(10.9)$ & $<0.001$ & 90 (14.5) & $232(14.2)$ & $75(12.1)$ & 0.420 & $67(27.6)$ & $200(15.9)$ & $130(9.5)$ & $<0.001$ \\
\hline 15 years & $67(15.4)$ & $194(10.9)$ & $71(10.1)$ & 0.014 & $71(11.2)$ & 186 (11.2) & 75 (12.0) & 0.860 & $49(19.7)$ & $156(12.2)$ & $127(9.1)$ & $<0.001$ \\
\hline 18 years & 71 (16.3) & $223(12.6)$ & 66 (9.3) & 0.002 & 75 (11.8) & 215 (13.0) & 70 (12.2) & 0.465 & 58 (23.3) & 165 (12.9) & 137 (9.8) & $<0.001$ \\
\hline 22 years & 68 (15.7) & 174 (9.8) & $50(7.1)$ & $<0.001$ & $61(9.6)$ & $162(9.8)$ & $69(11.1)$ & 0.618 & 69 (27.9) & $136(10.6)$ & $87(6.3)$ & $<0.001$ \\
\hline \multicolumn{13}{|c|}{ Asthma diagnosis } \\
\hline 4 years & $5(4.8)$ & $8(1.62)$ & $2(1.14)$ & 0.133 & $2(0.9)$ & $13(2.9)$ & - & 0.068 & $3(4.4)$ & $5(1.7)$ & 7 (1.8) & 0.404 \\
\hline 11 years & $158(37.1)$ & $481(27.5)$ & 162 (23.2) & $<0.001$ & $180(29.0)$ & $454(27.8)$ & $167(27.0)$ & 0.778 & $120(49.4)$ & $390(31.0)$ & 291 (21.2) & $<0.001$ \\
\hline 15 years & $161(37.1)$ & $516(29.1)$ & $162(23.0)$ & $<0.001$ & $188(29.6)$ & $480(30.0)$ & $171(27.4)$ & 0.675 & $124(50.0)$ & 409 (32.0) & 306 (22.5) & $<0.001$ \\
\hline 18 years & 125 (28.7) & $381(21.5)$ & 115 (16.3) & $<0.001$ & 125 (19.7) & $364(22.0)$ & $132(21.0)$ & 0.479 & $107(43.0)$ & 310 (24.3) & 204 (14.7) & $<0.001$ \\
\hline 22 years & $131(30.1)$ & 407 (22.9) & 120 (17.0) & $<0.001$ & $140(22.0)$ & $382(23.1)$ & $136(21.6)$ & 0.745 & $109(43.9)$ & 317 (24.8) & $232(16.7)$ & $<0.001$ \\
\hline \multicolumn{13}{|c|}{ Allergy diagnosis } \\
\hline 11 years & 79 (18.5) & $298(17.0)$ & $142(20.4)$ & 0.146 & 104 (16.7) & 293 (17.9) & 122 (19.9) & 0.343 & 58 (23.9) & 223 (17.7) & 238 (17.3) & 0.047 \\
\hline 15 years & $99(22.9)$ & $339(19.2)$ & $169(24.1)$ & 0.015 & $121(19.1)$ & 335 (20.3) & 151 (24.2) & 0.057 & 59 (23.9) & 270 (21.2) & 278 (20.1) & 0.375 \\
\hline 18 years & 92 (21.2) & $349(19.6)$ & $20.6(20.6)$ & 0.714 & 109 (17.2) & 350 (21.1) & 127 (20.3) & 0.111 & 68 (27.3) & 246 (19.2) & $272(19.6)$ & 0.012 \\
\hline 22 years & 97 (22.4) & $433(24.4)$ & 179 (25.4) & 0.520 & $128(20.2)$ & 422 (25.5) & 159 (25.5) & 0.024 & 75 (30.2) & $283(22.1)$ & 351 (25.3) & 0.012 \\
\hline \multicolumn{13}{|c|}{ Family history of asthma } \\
\hline 11 years & 165 (38.7) & $588(33.6)$ & 230 (33.0) & 0.100 & 222 (35.7) & 537 (32.8) & 224 (36.5) & 0.178 & 109 (44.8) & 465 (37.0) & 409 (29.8) & $<0.001$ \\
\hline \multicolumn{13}{|l|}{ Mother's smoke } \\
\hline After 6 months & 38 (24.7) & 193 (34.7) & 75 (40.2) & 0.147 & 64 (29.3) & 171 (33.4) & 71 (43.2) & 0.126 & 26 (31.3) & 139 (39.1) & 141 (31.0) & 0.08 \\
\hline 4 years & 32 (20.8) & $181(33.6)$ & $68(36.7)$ & 0.070 & 58 (26.3) & 159 (32.2) & 64 (39.9) & 0.125 & $25(34.6)$ & $121(33.6)$ & 135 (30.9) & 0.728 \\
\hline 11 years & $126(29.6)$ & $553(31.6)$ & $191(24.4)$ & 0.116 & $177(28.4)$ & 508 (31.0) & 185 (30.2) & 0.491 & 87 (35.8) & $390(31.0)$ & $393(28.6)$ & 0.059 \\
\hline 18 years & 93 (21.4) & 384 (21.8) & 160 (22.8) & 0.824 & $131(20.7)$ & 367 (22.3) & 139 (22.3) & 0.707 & $58(23.4)$ & 289 (22.7) & $290(21.0)$ & 0.471 \\
\hline
\end{tabular}


TABLE 2 Continued

\begin{tabular}{|c|c|c|c|c|c|c|c|c|c|c|c|c|}
\hline & \multicolumn{4}{|c|}{ FEV $_{1}$} & \multicolumn{4}{|c|}{ FVC } & \multicolumn{4}{|c|}{$\mathrm{FEV}_{1} / \mathrm{FVC}$} \\
\hline & $\begin{array}{c}\text { Low } \\
\mathrm{N}=435\end{array}$ & $\begin{array}{l}\text { Average } \\
\mathrm{N}=1776\end{array}$ & $\begin{array}{c}\text { High } \\
\mathrm{N}=706\end{array}$ & p-value & $\begin{array}{c}\text { Low } \\
\mathrm{N}=635\end{array}$ & $\begin{array}{l}\text { Average } \\
\mathrm{N}=1657\end{array}$ & $\begin{array}{c}\text { High } \\
\mathrm{N}=625\end{array}$ & p-value & $\begin{array}{l}\text { Low } \\
\mathrm{N}=249\end{array}$ & $\begin{array}{l}\text { Average } \\
\mathrm{N}=1279\end{array}$ & $\begin{array}{c}\text { High } \\
\mathrm{N}=1389\end{array}$ & p-value \\
\hline \multicolumn{13}{|l|}{ Father's smoke } \\
\hline After 6 months & $44(34.4)$ & 169 (32.9) & $54(29.9)$ & 0.519 & $66(35.8)$ & $150(30.6)$ & $51(32.9)$ & 0.347 & $22(28.4)$ & 95 (29.7) & $150(34.8)$ & 0.335 \\
\hline 4 years & 38 (28.9) & $143(28.6)$ & $46(24.8)$ & 0.609 & $55(29.1)$ & $131(27.4)$ & $41(27.2)$ & 0.549 & 22 (31.7) & $83(25.1)$ & $122(29.3)$ & 0.418 \\
\hline 11 years & $124(38.6)$ & $502(37.1)$ & $190(34.4)$ & 0.395 & 174 (37.1) & 464 (36.2) & 178 (37.3) & 0.889 & 67 (36.2) & $361(36.9)$ & 388 (36.5) & 0.963 \\
\hline 18 years & 74 (17.0) & 269 (15.2) & $113(16.1)$ & 0.625 & $94(14.9)$ & 267 (16.2) & 95 (15.3) & 0.695 & 36 (14.5) & 195 (15.3) & 225 (16.9) & 0.691 \\
\hline \multicolumn{13}{|c|}{ Household smoke exposure } \\
\hline 18 years & $196(45.2)$ & 745 (42.2) & $299(42.6)$ & 0.546 & 264 (41.8) & 715 (43.4) & $261(42.1)$ & 0.708 & $108(43.6)$ & 549 (43.2) & $583(42.2)$ & 0.842 \\
\hline 22 years & $137(31.6)$ & 569 (32.1) & 212 (29.9) & 0.607 & $194(30.6)$ & 528 (31.9) & 196 (31.4) & 0.838 & 84 (33.9) & 391 (30.6) & 443 (31.9) & 0.527 \\
\hline \multicolumn{13}{|l|}{ Current smoker } \\
\hline 18 years & $55(12.6)$ & 230 (12.9) & 96 (13.6) & 0.876 & 71 (11.2) & 212 (12.8) & 98 (15.7) & 0.054 & $50(20.1)$ & 192 (15.0) & $139(10.0)$ & $<0.001$ \\
\hline 22 years & 80 (18.4) & $291(16.4)$ & $100(14.6)$ & 0.153 & $86(13.6)$ & $274(16.6)$ & 111 (17.8) & 0.103 & 64 (25.8) & 235 (18.4) & $471(16.1)$ & $<0.001$ \\
\hline \multicolumn{13}{|c|}{ Physical activity min } \\
\hline 11 years & $431.0 \pm 24.3$ & $432.2 \pm 11.0$ & $440.8 \pm 18.9$ & 0.911 & $421.2 \pm 18.7$ & $432.6 \pm 11.5$ & $450.9 \pm 20.6$ & 0.535 & $458.9 \pm 32.3$ & $461.1 \pm 14.0$ & $404.9 \pm 12.1$ & 0.007 \\
\hline 15 years & $482.9 \pm 26.2$ & $438.7 \pm 11.7$ & $455.1 \pm 18.0$ & 0.239 & $434.5 \pm 18.0$ & $437.7 \pm 18.1$ & $468.1 \pm 20.5$ & 0.516 & $525.6 \pm 42.2$ & $481.2 \pm 14.4$ & $406.2 \pm 11.9$ & $<0.001$ \\
\hline 18 years & $643.4 \pm 31.0$ & $658.3 \pm 19.8$ & $683.7 \pm 27.4$ & 0.663 & $639.1 \pm 28.9$ & $658.8 \pm 20.2$ & $694.8 \pm 29.8$ & 0.435 & $771.8 \pm 47.7$ & $676.8 . \pm 20.4$ & $629.2 \pm 22.4$ & 0.021 \\
\hline 22 years & $377.8 \pm 24.8$ & $335.7 \pm 10.2$ & $335.3 \pm 13.5$ & 0.163 & $359.3 \pm 20.0$ & $335.7 \pm 10.1$ & $340.4 \pm 15.2$ & 0.495 & $379.1 \pm 31.5$ & $352.9 \pm 12.0$ & $325.1 \pm 11.0$ & 0.088 \\
\hline
\end{tabular}

Data are presented as $\mathrm{n}(\%)$ or mean $\pm \mathrm{SD}$, unless otherwise stated. $\mathrm{p}$-values were obtained by the Chi-squared test, unless otherwise stated. FEV $\mathrm{V}_{1}$ : forced expiratory volume in $1 \mathrm{~s}$; FVC: forced vital capacity. ${ }^{\#}$ : p-value was obtained by ANOVA (mean \pm sD). Due to sample design at 6 and 12 months and 4 years of age lall births $<2500 \mathrm{~g}$ and a $20 \%$ sample of the remaining children), relative frequencies were weighted to reproduce the original cohort distribution. $\mathrm{N}$ : absolute frequencies of individuals per pulmonary function (PF) trajectories based on the total sample (2197); $n$ : absolute frequencies of the exposure covariables per PF trajectory. Total sample at 6 and 12 months and at 4 and 11 years of age with PF measurements at all three follow-ups was $830,813,755$ and 1876 , respectively. 

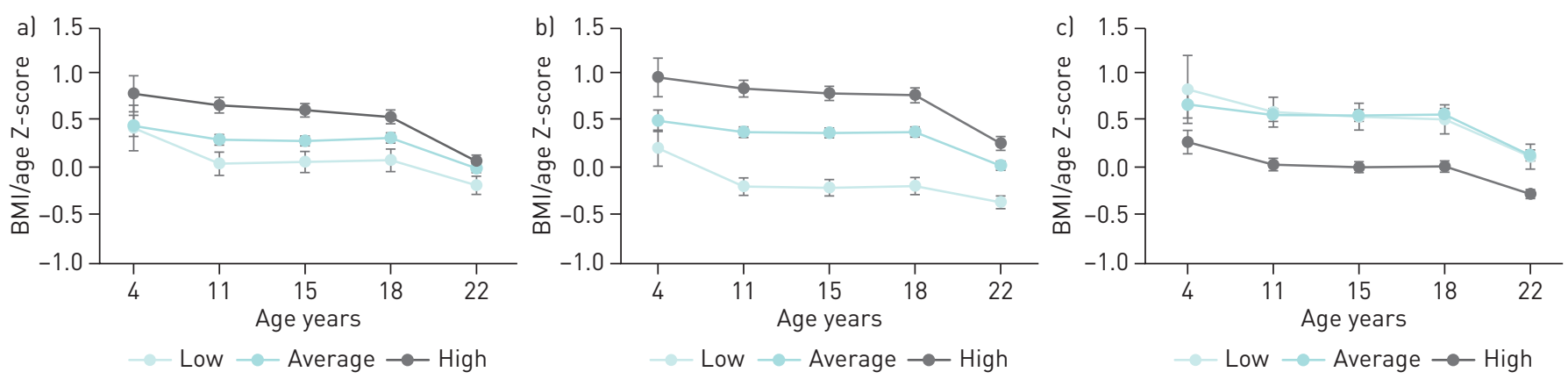

FIGURE $2 \mathrm{BMI} /$ age (z-scores) and pulmonary function (PF) trajectories based on al forced expiratory volume in $1 \mathrm{~s}\left(\mathrm{FEV}{ }_{1}\right.$ ); b) forced vital capacity (FVC) and c) FEV $1 / F V C$ ratio.

Mother's smoke exposure during pregnancy (table 1) and current smoking at 18 and 22 years (table 2) were related to the $\mathrm{LT}$ of $\mathrm{FEV}_{1} / \mathrm{FVC}$ ratio. There is clear evidence that in utero tobacco exposure results in $\mathrm{PF}$ deficits in infancy that tracks into adulthood [29]. It was already associated with a reduction in $\mathrm{FEV}_{1}$ in 21-year-old men [30] and in the $\mathrm{FEV}_{1} / \mathrm{FVC}$ ratio measured at 16 years [31]. The TAHS study [3] showed that current smoking status was associated with submaximal PF trajectories at adulthood and an interaction between maternal and personal smoking for the risk of belonging to the lower PF trajectory. Despite not being statistically significant, higher smoke exposure was related to the HT of FVC (table 2). However, lower values of $\mathrm{FEV}_{1} / \mathrm{FVC}$ ratio were also shown in this trajectory (figure 3 ). Thus, our findings demonstrated agreement between high $\mathrm{FVC}$ and low $\mathrm{FEV}_{1} / \mathrm{FVC}$ trajectories as complementary signals for airflow obstruction and its relation to tobacco smoke exposure. The same pattern was already described; while the FVC level was higher in smokers, the rates of FVC and $\mathrm{FEV}_{1}$ growth were reduced [32].

Regarding the history of respiratory conditions, the frequency of hospitalisations due to respiratory diseases was significantly higher in the $\mathrm{LT}$ of $\mathrm{FEV}_{1}$ and $\mathrm{FEV}_{1} / \mathrm{FVC}$ ratio. Similarly, in the MAAS cohort [7], the proportion of children with lower respiratory tract infections in the first 3 years of life was higher in the persistently LT of $\mathrm{FEV}_{1}$ compared to the normal trajectory. Also, the proportion of bronchitis and pneumonia was higher in the three trajectories represented by always below average values of PF in the TAHS study [3]. The diagnoses of asthma, allergy and wheezing were associated with the LT of FEV $\mathrm{F}_{1}$ and $\mathrm{FEV}_{1} / \mathrm{FVC}$ (table 2). The MASS and ALSPAC cohorts [7] also identified associations between a reduced $\mathrm{FEV}_{1}$ trajectory with wheezing and asthma. Similarly, in the TAHS study [3], individuals whose PF was considered persistently below average had a higher prevalence of asthma and in the IOW cohort [9], asthma was related to the lower trajectories of $\mathrm{FEV}_{1}, \mathrm{FEV}_{1} / \mathrm{FVC}$ and forced expiratory flow at 25-75\% of FVC in men. A meta-analysis [33] enrolling large samples of wheezing and nonwheezing children, concluded a reduction in $\mathrm{FEV}_{1}$ and $\mathrm{FEV}_{1} / \mathrm{FVC}$ ratio in adulthood between those who reported wheezing. Indeed, the same pattern was observed in our sample. The family history of asthma was associated with the $\mathrm{LT}$ of $\mathrm{FEV}_{1} / \mathrm{FVC}$ ratio (table 2). Another study associated paternal asthma with a lower increase in $\mathrm{FEV}_{1}$ and low $\mathrm{FEV}_{1} / \mathrm{FVC}$ ratio from 8 to 16 years [34]. In the CRS cohort, individuals with a persistently low PF trajectory were more likely to have asthmatic mothers [8].
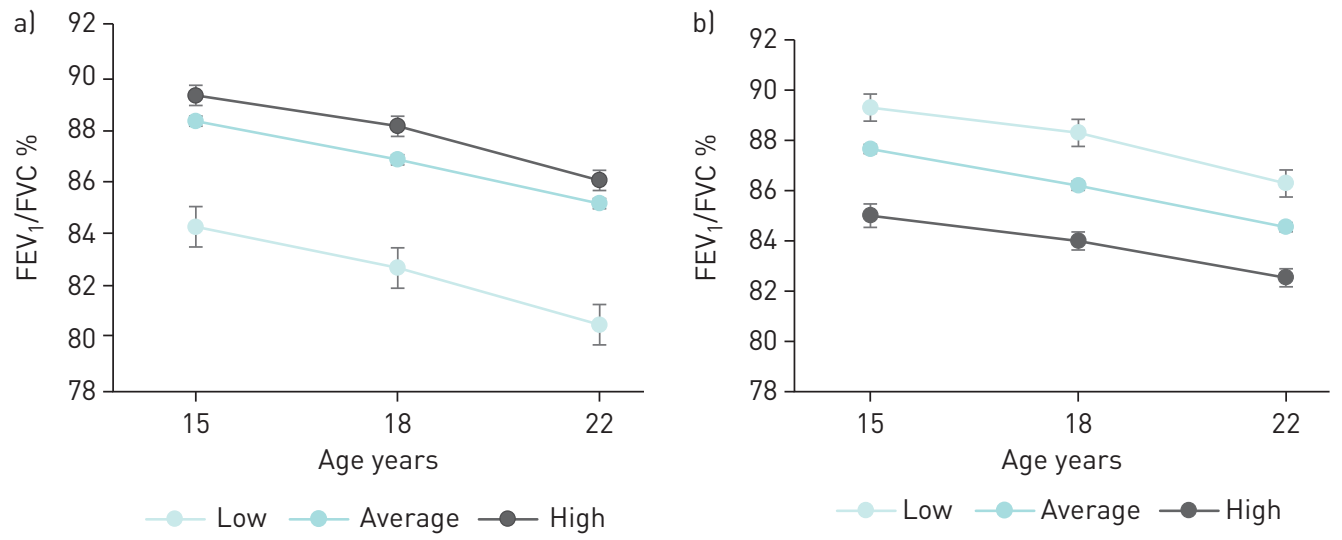

FIGURE 3 Description of the forced expiratory volume in $1 \mathrm{~s}\left(\mathrm{FEV}_{1}\right) /$ forced vital capacity (FVC) ratio means for each trajectory group based on a) $\mathrm{FEV}_{1}$ and b) FVC. 
At all ages, higher BMI means were linked to the $\mathrm{HT}$ of $\mathrm{FEV}_{1}$ and FVC (figure 2). A study [35], showed higher lean BMI (LBMI) related to PF growth and higher fat mass index (FMI) was associated with worse $\mathrm{FEV}_{1}$ in boys and $\mathrm{FEV}_{1} / \mathrm{FVC}$ in both sexes. As an increase in both LBMI and FMI will increase BMI, and these findings support that BMI itself may be insufficient to explore the relationship between body composition and PF growth. The higher BMI observed in the higher trajectories in our study may be due to a higher percentage of fat-free mass in these individuals rather than obesity. This can be supported by previous results obtained in this same cohort where individuals in the highest tertile of fat mass at 18 and 22 years old presented poorer PF at age 22 years compared to those who were in the lowest tertile [36].

More active people were associated with the $\mathrm{LT}$ of $\mathrm{FEV}_{1} / \mathrm{FVC}$ ratio. Physical activity defined by accelerometry has been linked to better PF at 15 years [37]. However, earlier work in our cohort [38] showed no evidence that more active individuals have better PF at 18 years. We only assessed physical activity through self-report and only during commuting and in leisure time. Although we do not refute the possibility of reverse causation in this relationship, we strongly believe that objective measurements of physical activity may better explain its association with PF.

Our study has some limitations. The first refers to differences between respondents (55.6\%) and nonrespondents $(44.4 \%)$, which showed that our sample included more children from wealthier and more educated mothers. However, this probably will have a very small impact on our results, as the socioeconomic status was weakly related to the PF trajectories. Another limitation is related to the self-reported nature of some variables. Diagnosis of asthma and wheezing may be underestimated and physical activity overestimated. With this, the probability increases of not finding a statistical difference. However, there are also considerable strengths. A cohort of live births, representative of the urban area of the municipality and with high response rates, allows the extrapolation of the results to similar settings. The measurements of PF, by trained personnel, allowed the comparability of assessments. Finally, training and re-training of interviewers and repetition of questions to assess reliability ensured the quality of the information.

Although admittedly exploratory, our study adds to the current knowledge as being the first one to address PF trajectories along with several characteristics accessed from perinatal to early adult age in a middle-income setting. The practical relevance of it is the possibility of screening those who fill a risky profile to low PF trajectories in a crucial period of lung development and consequently prevent future respiratory diseases. After being for many years considered a self-inflicted disease by smokers, we now know from longitudinal studies that COPD burden is also related to many factors during the lifespan that culminates in low PF in young adulthood [39]. In addition, keeping in mind the raising of knowledge that PF tracks throughout life, special attention should be given to those individuals belonging to the low trajectories of $\mathrm{PF}$ who consequently present a higher risk of developing respiratory diseases such as COPD later in life [40].

\section{Conclusion}

Using data from a population-based birth cohort from Brazil, we identified three PF trajectories (low, average and high) in the following parameters: $\mathrm{FEV}_{1}, \mathrm{FVC}$ and $\mathrm{FEV}_{1} / \mathrm{FVC}$ ratio, which tracked from the middle of adolescence to the onset of adult life. They were related to different characteristics, including pregestational BMI, birth weight, hospitalisations due to respiratory diseases in childhood, participant's BMI along with follow-ups, report of wheezing, medical diagnosis and family history of asthma, gestational exposure to tobacco and active smoking in adolescence and young adulthood. Public health policies can be planned to control or at least minimise the exposure to such characteristics in order to guarantee that more individuals reach adulthood with ideal values of PF.

Conflict of interest: P. Weber reports personal fees from Coordination of Improvement of Higher-Level Personnel (CAPES) during the conduct of the study. A.M.B. Menezes has nothing to disclose. H. Gonçalves has nothing to disclose. R. Perez-Padilla has nothing to disclose. D. Jarvis has nothing to disclose. P.D. de Oliveira has nothing to disclose. F.C. Wehrmeister reports a scholarship for productivity in research from $\mathrm{CNPq}$ during the conduct of the study.

Support statement: This study was financed in part by the Coordination for the Improvement of Higher Education Personnel - Brazil (CAPES). This article is based on data from the study "Pelotas Birth Cohort, 1993" conducted by the Postgraduate Program in Epidemiology of the Federal University of Pelotas with the collaboration of the Brazilian Public Health Association. From 2004 to 2013, the Wellcome Trust supported the 1993 birth cohort study. The European Union, National Support Program for Centres of Excellence, Brazilian National Research Council for Scientific and Technological Development (CNPq) and the Brazilian Ministry of Health supported previous phases of the study. The 22-year follow-up was supported by the Science and Technology Department/Brazilian Ministry of Health. Funding information for this article has been deposited with the Crossref Funder Registry. 


\section{References}

1 Fletcher C, Peto R. The natural history of chronic airflow obstruction. $\mathrm{Br}$ Med J 1977; 1: 1645-1648.

2 Bui DS, Burgess JA, Lowe AJ, et al. Childhood lung function predicts adult chronic obstructive pulmonary disease and asthma-chronic obstructive pulmonary disease overlap syndrome. Am J Respir Crit Care Med 2017; 196: 39-46.

3 Bui DS, Lodge CJ, Burgess JA, et al. Childhood predictors of lung function trajectories and future COPD risk: a prospective cohort study from the first to the sixth decade of life. Lancet Respir Med 2018; 6: 535-544.

4 Agusti A, Faner R. Lung function trajectories in health and disease. Lancet Respir Med 2019; 7: 358-364.

5 Lange P, Celli B, Agustí A, et al. Lung-function trajectories leading to chronic obstructive pulmonary disease N Engl J Med 2015; 373: 111-122.

6 Agustí A, Noell G, Brugada J, et al. Lung function in early adulthood and health in later life: a transgenerational cohort analysis. Lancet Respir Med 2017; 5: 935-945.

7 Belgrave DCM, Granell R, Turner SW, et al. Lung function trajectories from pre-school age to adulthood and their associations with early life factors: a retrospective analysis of three population-based birth cohort studies. Lancet Respir Med 2018; 6: 526-534.

8 Berry CE, Billheimer D, Jenkins IC, et al. A distinct low lung function trajectory from childhood to the fourth decade of life. Am J Respir Crit Care Med 2016; 194: 607-612.

9 Karmaus W, Mukherjee N, Janjanam VD, et al. Distinctive lung function trajectories from age 10 to 26 years in men and women and associated early life risk factors-a birth cohort study. Respir Res 2019; 20 : 98.

10 Menezes AMB, Perez-Padilla R, Wehrmeister FC, et al. FEV 1 is a better predictor of mortality than FVC: the PLATINO Cohort Study. PLoS ONE 2014; 9: e109732.

11 Kang HS, Shin AY, Yeo CD, et al. A lower level of forced expiratory volume in one second predicts the poor prognosis of small cell lung cancer. J Thorac Dis 2018; 10: 2179-2185.

12 Knuiman MW, James AL, Divitini ML, et al. Lung function, respiratory symptoms, and mortality: results from the Busselton Health Study. Ann Epidemiol 1999; 9: 297-306.

13 Duong M, Islam S, Rangarajan S, et al. Mortality and cardiovascular and respiratory morbidity in individuals with impaired $\mathrm{FEV}_{1}$ (PURE): an international, community-based cohort study. Lancet Glob Health 2019; 7: 613-623.

14 Gonçalves H, Wehrmeister FC, Assunção MC, et al. Cohort profile update: the 1993 Pelotas (Brazil) Birth Cohort follow-up at 22 years. Int J Epidemiol 2017; 47: 1389-1390.

15 Miller MR, Crapo R, Hankinson J, et al. General considerations for lung function testing. Eur Respir J 2005; 26: $153-161$.

16 Miller MR, Hankinson J, Brusasco V, et al. Standardisation of spirometry. Eur Respir J 2005; 26: 319-338.

17 World Health Organization. Physical status: the use of and interpretation of anthropometry. Report of a WHO Expert Committee. Geneva, WHO, 1995.

18 World Health Organization. Growth reference data for 5-19 years. Geneva, World Health Organization, 2007.

19 Hallal PC, Victora CG. Reliability and validity of the international physical activity questionnaire (IPAQ). Med Sci Sports Exerc 2004; 36: 556

20 World Health Organization. Global recommendations on physical activity for health. Geneva, WHO, 2010.

21 Jones BL, Nagin DS. A note on a Stata plugin for estimating group-based trajectory models. Sociol Methods Res 2013; 42: 608-613.

22 Jones BL, Nagin DS, Roeder K. A SAS procedure based on mixture models for estimating developmental trajectories. Sociol Methods Res 2001; 29: 374-393.

23 Nagin DS, Odgers CL. Group-based trajectory modeling in clinical research. Ann Rev Clin Psychol 2010; 6: $109-138$

24 Oksel C, Granell R, Mahmoud O, et al. Causes of variability in latent phenotypes of childhood wheeze. J Allergy Clin Immunol 2019; 143: 1783-90 e11.

25 Rocha V, Soares S, Stringhini S, et al. Socioeconomic circumstances and respiratory function from childhood to early adulthood: a systematic review and meta-analysis. BMI 2019; 9; e027528.

26 Menezes AM, Dumith SC, Perez-Padilla R, et al. Socioeconomic trajectory from birth to adolescence and lung function: prospective birth cohort study. BMC Public Health 2011; 11: 596.

27 Stocks J, Hislop A, Sonnappa S. Early lung development: lifelong effect on respiratory health and disease. Lancet Respir Med 2013; 1: 728-742.

28 Saad NJ, Patel J, Burney P, et al. Birth weight and lung function in adulthood: a systematic review and meta-analysis. Ann Am Thorac Soc 2017; 14: 994-1004.

29 Landau LI. Tobacco smoke exposure and tracking of lung function into adult life. Paediatr Respir Rev 2008; 9 39-44.

30 Hayatbakhsh MR, Sadasivam S, Mamun AA, et al. Maternal smoking during and after pregnancy and lung function in early adulthood: a prospective study. Thorax 2009; 64: 810-814.

31 Thacher JD, Schultz ES, Hallberg J, et al. Tobacco smoke exposure in early life and adolescence in relation to lung function. Eur Respir J 2018; 51: 1702111.

32 Gold DR, Wang X, Wypij D, et al. Effects of cigarette smoking on lung function in adolescent boys and girls N Engl J Med 1996; 335: 931-937.

33 Ma H, Li Y, Tang L, et al. Impact of childhood wheezing on lung function in adulthood: a meta-analysis. PLoS One 2018; 13: 0192390.

34 Schultz ES, Hallberg J, Andersson N, et al. Early life determinants of lung function change from childhood to adolescence. Respir Med 2018; 139: 48-54.

35 Peralta GP, Fuertes E, Granell R, et al. Childhood body composition trajectories and adolescent lung function: findings from the ALSPAC study. Am J Respir Crit Care Med 2019; 200: 75-83.

36 Oliveira PD, Wehrmeister FC, Gonçalves H, et al. Body composition from 18 to 22 years and pulmonary function at 22 years-1993 Pelotas Birth Cohort. PLoS ONE 2019; 14: e0219077.

37 Roda C, Mahmoud O, Peralta GP, et al. Physical-Activity trajectories during childhood and lung function at 15 years: findings from the ALSPAC cohort. Int J Epidemiol 2019; 1: 11.

38 da Silva BGC, Menezes AM, Wehrmeister FC, et al. Screen-based sedentary behavior during adolescence and pulmonary function in a birth cohort. Int Jour Behav Nutr Phys Act 2017; 14: 82. 
39 Postma DS, Bush A, van den Berge M. Risk factors and early origins of chronic obstructive pulmonary disease. Lancet 2015; 385: 899-909.

40 Sly PD, Bush A. From the cradle to the grave: the early-life origins of chronic obstructive pulmonary disease. Am Thorac Soc 2016; 93: 1-2. 